\title{
23-Gauge vitrectomy for retinal detachment with upper and lower retinal breaks A comparative study
}

\author{
Khaled Hamdi Elbaklish \\ Assistant prof in ophthalmology department \\ Ain Shams University \\ Cairo Egypt \\ khaled.hamdy62@yahoo.com \\ DOI: 10.31364/SCIRJ/v9.i01.2021.P0121837 \\ http://dx.doi.org/10.31364/SCIRJ/v9.i01.2021.P0121837
}

\section{Abstract-}

Purpose: To compare the anatomic and visual outcomes of upper retinal break detachment and lower retinal break detachment after 23-gauge vitrectomy.

Methods: Fifty participants with retinal detachment were assigned and divided into two groups. Twenty patients with upper retinal break detachment were recruited into group A and 30 patients with lower retinal break detachment were recruited into group B. 23- Gauge vitrectomy and silicone oil removal were performed to all participants. The primary outcome measure was the failure rate, defined as the retina was detached in silicone filled eye or within 6 weeks after silicone removal. A range of secondary outcomes were determined, including risk factors like the retinal breaks location, laser applied around the breaks, and complications following retinal detachment surgery. The final visual acuity was assessed.

Results: The failure rate after 23-gauge vitrectomy was (15/50) 0.3; fifteen had recurrent detachment (3cases- group A, 12 cases group $\mathrm{B})(\mathrm{P}=.047)$. After two 23-gauge vitrectomy three had recurrent $\mathrm{RD}$ in group $\mathrm{B}(\mathrm{P}=.083)$. More than two procedures did for three cases of group $\mathrm{B}$. Proliferative vitreoretinopathy is the significant risk factor with weak clinical effect. The final visual acuity at 6 months after SO removal in all participants in both groups was not significant $(\mathrm{P}=.099)$. Survival analysis revealed that, the time onset of postoperative retinal detachment in the first 3-6 months after silicone oil removal has no statistical difference between both groups $\mathrm{A}$ and $\mathrm{B}(\mathrm{P}=.404)$

Conclusions: The first 23- Gauge vitrectomy has less failure rate in upper retinal break detachment compared with lower retinal break detachment. Proliferative vitreoretinopathy is the significant risk factor for recurrent RD. All participants have good visual acuity at 6 months after SO removal compared with the preoperative visual acuity.
Key Words: vitrectomy-silicone- retina- breaksproliferation-detachment-upper-lower.

\section{INTRODUCTION}

23- Gauge pars plana vitrectomy (PPV) improves the visualization of the peripheral retina, the detection of small retinal breaks in the periphery and allowing complete vitreous removal in phakic and pseudophakic $\mathrm{RD}^{1,2}$.

Inferior retinal breaks can be treated with 23 -gauge vitrectomy without additional scleral buckle. The difficulty in inferior vitreous management in phakic, pseudophakic eyes, the questionable direct tamponading effect, and the higher rate of redetachment after pars plana vitrectomy, are the problems of the procedure . $^{3}$

After 23 gauge vitrectomy, the patients lie erect or sit to keep the long contact between gas/silicone bubbles with the superior retinal breaks. The situation is complicated if we will do vitrectomy without buckling in inferior retinal breaks. We need nearly full gas/silicone bubble and special positioning ${ }^{4}$.

In silicone filled eye, there is reproliferation under the bubble.This is may be harmful to the inferior retina especially if lower retinal breaks are present. The statement that, we don't need tamponade if all breaks are closed and there is no traction. This statement is questionable ${ }^{5}$.

In this paper, we report the anatomic and visual outcomes after 23-gauge vitrectomy for upper retinal break detachment (group A) and lower retinal break detachment (group B). 


\section{METHODS AND SUBJECTS}

This was a prospective and randomized study. The study protocol was approved by the Ethics Committee of Ain Shams University (FWA 000017585 and FMASU R25/2017). The study was carried out in accordance with the tenets of the Declaration of Helsinki, and all participants provided written and informed consent to participate. Patients were included if they had upper or lower retinal breaks. These breaks were associated with $\mathrm{RD}$, moderate degrees of proliferative vitreoretinopathy (PVR $\geq$ GradeC). We were accepting cases with previous buckle surgery or pseudophakia. Patients were excluded if the retinal tear was giant, presence of intravitreal foreign body, previous vitrectomy done before, cases that need relaxing retinotomies or retinectomy or if follow-up data were unavailable for a minimum follow-up of 6 months following the final retinal procedure. All participants recruited and admitted to Ain Shams Specialized Hospital and eye centers between November 2011 and October 2015.

\section{RANDOMIZATION AND TREATMENT}

In this study, our intention was to identify surgical failures, risk factors, visual outcomes, intraoperative and postoperative complications in both groups A and B. All surgeries did by single surgeon. This minimized other confounding factors, such as surgical experience. To do this, we screened all participants, recruited those who met our specific inclusion criteria, and obtained written and informed consent to participate. Each of the recruited patients were assigned a study number and randomized in accordance with a simple block randomization scheme.

\section{SURGICAL PROCEDURES}

23- Gauge vitrectomy was performed to all participants as previously described ${ }^{6}$. The surgical technique consisted of

- Removal of vitreous gel

-Induction of posterior vitreous detachment (PVD) was done (if posterior hyaloid face was still attached)

-Installation of heavy perfluorocarbon liquids

-Identification and marking of retinal breaks

-Internal drainage of subretinal fluid and Air infusion

-Laser treatment of retinal breaks

-Silicone oil (SO) injection

-Closure of sclerotomies and conjunctival closure

In group A, we removed the vitreous around the breaks thoroughly and apply laser at the edge of the break and three rows around the break.

In group B, we removed the vitreous around the break. Tano scraper was used to remove the epiretinal membranes and residual hyaloid face. Laser applied to the edge of the break, three rows around the break and extended to the ora serrata.

- Three -six months after 23- gauge vitrectomy, SO was removed in all participants.

\section{PATIENT VISITS}

After 3-6 months we removed the silicone and examined the retina for 6 months after surgery. Patients were followed-up for 6 months after 23 gauge procedures and SO removal. At each follow-up visit, we analyzed a range of variables, including visual acuity, fundus examination, IOP, slit lamp examination, and the incidence of intraoperative and postoperative complications. We used B-scan to detect early recurrence in suspicious cases with hazy media. Early admission for second interference was done. All retinal redetachment operations were performed at the time of SO removal or after and silicone oil was injected again. The primary outcome measure was the failure rate, defined as the retina was detached in silicone filled eye or within 6 weeks after SO removal. A range of secondary outcomes were also determined, including risk factors like the retinal breaks location, laser applied around the breaks, and complications following RD surgery. The best visual acuity during the follow-up period and the final visual acuity were assessed.

\section{STATISTICAL ANALYSIS}

Demographic data of the participants were estimated with Mann-Whitney, independent T-test and chi-square test of independence. Fifty participants with RD were assigned and divided into two groups. Twenty patients with upper retinal break detachment were recruited into group A and 30 patients with lower retinal break detachment were recruited into group B. General linear model with multivariate analysis was used to compare the risk factors in the two groups. Survival time of the retinal stability was calculated from the date of the operation to the date of retinal redetachment or last follow-up, and survival curves were constructed using the Kaplan-Meier method. The final retinal reattachment, best and final visual acuity were analyzed using the Pearson chi-squared test or 2sided independent $\mathrm{t}$ - test. The sample size was determined from the results of previous studies with an alpha of 0.05 and $80 \%$ power (two-tailed), a $15 \%$ difference in the incidence of $\mathrm{RD}^{7}$. $\mathrm{P}$ - Values lower than 0.05 were considered statistically significant.

\section{RESULTS}

Patients were recruited and randomly assigned into group A and group B. The mean age was 41.86 years. In group A, the mean age was 42.37 years. In group $B$, the mean age was 40.67years. In group A (20 participants), 11 patients were females and 9 were males; compared to 16 females and 14 males in groupB (30 participants). The identified retinal breaks in 50 cases were horseshoe tears, retinal dialysis ,round holes with opercula, round holes without opercula (atrophic Holes) and lattice degeneration.these breaks were distributed as upper temporal retinal breaks in10 participants, 12 o'clock breaks in 4 participants, upper nasal retinal breaks in6 participants and lower retinal breaks in30 participants. These breaks were being single or multiple in this sample of patients. All participants had macular detachment at the time of diagnosis. There was significant difference in PVR state before surgery in both groups $(\mathrm{P}=.001)$. During surgery, iatrogenic retinal breaks (related to separation of posterior hyaloid with Tano scrapper) occurred in 3 cases in group B. We did drainage 
retinotomy in 10 cases (group A-4 cases, group B- 6 cases). A retinal detachment was detected in silicone filled eye after 23- gauge vitrectomy in two cases of group B (Lower $\mathrm{RD})$.

Baseline demographic and ocular characteristics were similar during comparison between both groups (Table- 1).

\begin{tabular}{|c|c|c|c|}
\hline $\begin{array}{l}\text { Demographic } \\
\text { and clinical } \\
\text { characteristics }\end{array}$ & $\begin{array}{c}\text { Group A- } \\
20 \text { Cases }\end{array}$ & $\begin{array}{l}\text { Group B- } \\
\text { 30 Cases }\end{array}$ & p-Value \\
\hline Ages & $41.96 \pm 7.91$ & $41.7 \pm 5.77$ & $.92^{*}$ \\
\hline $\begin{array}{l}\text { Sex, } n(\%) \\
\text { Female } \\
\text { Male }\end{array}$ & $\begin{array}{l}55 \%(11 \mathrm{~F}) \\
45 \%(9 \mathrm{M})\end{array}$ & $\begin{array}{l}53 \% \quad(16 \\
\mathrm{F}) \\
47 \% \\
(14 \mathrm{M})\end{array}$ & $.91{ }^{* *}$ \\
\hline $\begin{array}{l}\text { Trauma with } \\
\text { retinal } \\
\text { detachment }\end{array}$ & $2 / 20$ & $2 / 30$ & \\
\hline $\begin{array}{l}\text { Myopia with } \\
\text { retinal } \\
\text { detachment }\end{array}$ & $1 / 20$ & $2 / 30$ & \\
\hline $\begin{array}{l}\text { Initial } \quad \text { PVR- } \\
\text { stage: } \\
\text { A+B } \\
\text { C }\end{array}$ & $\begin{array}{l}18 / 20 \\
2 / 20\end{array}$ & $\begin{array}{l}10 / 30 \\
20 / 30\end{array}$ & $.001^{*}$ \\
\hline Phakic eyes & $18 / 20$ & $28 / 30$ & $.7^{*}$ \\
\hline $\begin{array}{l}\text { Preceding } \\
\text { Buckling } \\
\text { procedure }\end{array}$ & $2 / 20$ & $4 / 30$ & $.697^{*}$ \\
\hline $\begin{array}{l}\text { horseshoe } \\
\text { tears } \\
\text { single } \\
\text { more than } \\
\text { one }\end{array}$ & $\begin{array}{l}12 \text { cases } \\
-8 \text { cases } \\
-4 \text { cases }\end{array}$ & $\begin{array}{l}10 \text { cases } \\
-8 \text { cases } \\
-2 \text { cases }\end{array}$ & $.065^{*}$ \\
\hline $\begin{array}{l}\text { retinal } \\
\text { dialysis }\end{array}$ & 2 cases & 2 cases & \\
\hline $\begin{array}{l}\text { round Holes } \\
\text { with } \\
\text { Opercula, }\end{array}$ & 2 cases & 6 cases & $.355^{*}$ \\
\hline single & - & -2cases & \\
\hline $\begin{array}{l}\text { more than } \\
\text { one }\end{array}$ & -2 cases & -4cases & \\
\hline $\begin{array}{l}\text { round Holes } \\
\text { without } \\
\text { Opercula } \\
\text { (Atrophic } \\
\text { Holes) } \\
\text { single } \\
\text { more than } \\
\text { one }\end{array}$ & $\begin{array}{l}- \\
-1 \text { case }\end{array}$ & $\begin{array}{l}- \\
-6 \text { cases }\end{array}$ & $.14^{*}$ \\
\hline lattice & 3 cases & 6 cases & \\
\hline
\end{tabular}

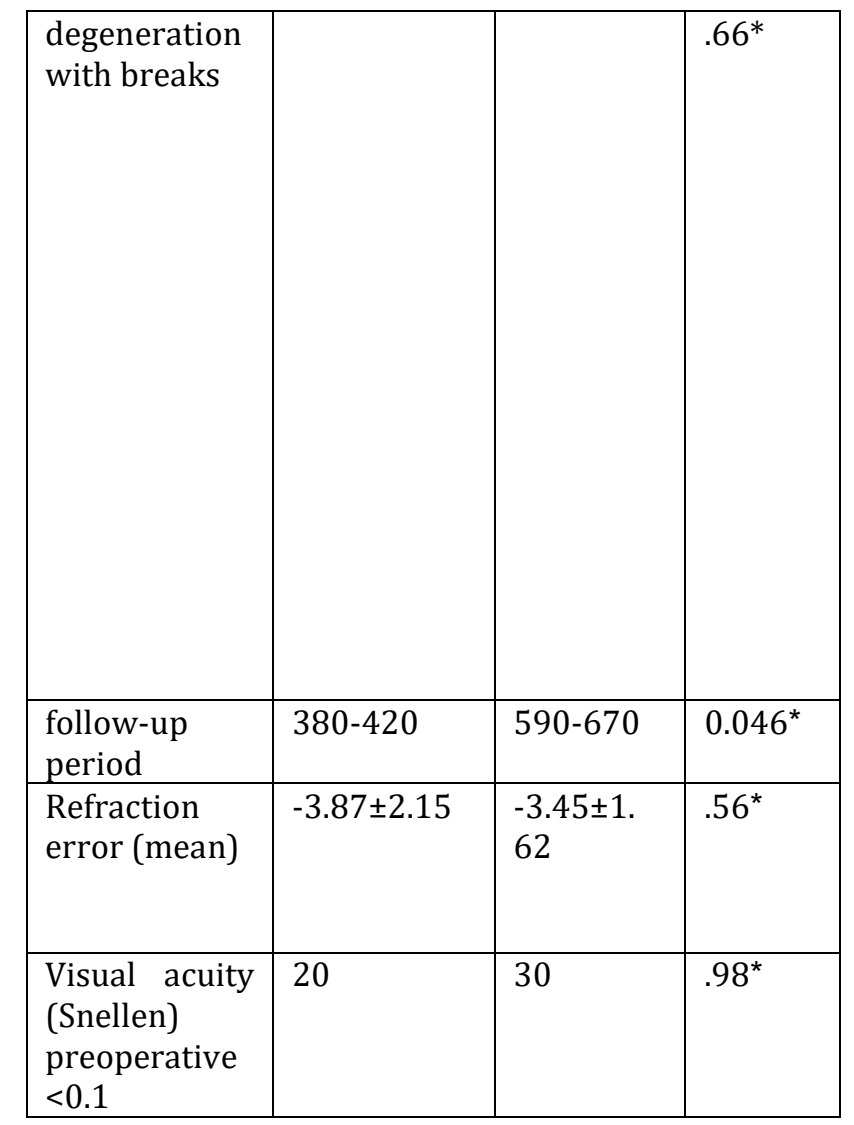

Table -1.Data show the baseline demographic and clinical characteristics of patients in both groups of the study.

*assessed by independent $\mathrm{t}-$ test.

** assessed by chi-square test of independence.

After SO removal, the retina was completely reattached in 35/50 (group A- 17cases, group B- 18 cases). The failure rate after the first 23-gauge vitrectomy was (15/50) 0.3 (group A-3cases, groupB-12 cases $(\mathrm{P}=.047)$ ). In recurrent $\mathrm{RD}$ group (15 cases), the failure rate was 0.2 . Twelve participants had flat retina after SO removal. Three cases of group A and nine cases of group B after two 23gauge procedures had flat retina $(\mathrm{P}=.083)$.

Three cases of group B (recurrent RD group) needed more than two procedures.

The reattachment rate in both groups was affected by PVR, and reopening of retinal defects or developing new defect related to membrane proliferation. Reproliferations like epiretinal membranes, subretinal membranes and PVR grade C,D in (11/15 cases group B) had a statistically significant effect in group $\mathrm{B}(\mathrm{P}=.000)$. Another causes of failure were missed or new breaks (group A- 2 cases, group B- one case), and inadequate silicone filling (group A- one case). Multivariate analysis was performed to assess preoperative, intraoperative and postoperative risk factors for 23-gauge vitrectomy. Proliferative vitreoretinopathy is the significant risk factor with weak clinical effect on comparing group $\mathrm{A}$ and group $\mathrm{B}(\mathrm{P}<.000)$. Patient's age , refraction ,previous history of trauma, types of breaks, the state of lens (phakic or pseudophakic), iatrogenic breaks, and drainage retinotomy were not risk factors. The difference in visual acuity at 6 months (the final visual 
acuity) after SO removal in all participants in both groups was not significant $(\mathrm{P}=.099)$. Table- 2

The final visual acuity was reported after one procedure (23-gauge vitrectomy) in 35 participants and repeated procedures (23-gauge vitrectomy) in 15 participants. Visual acuity ranged from $20 / 60$ to $20 / 400$ in both group participants. The visual acuity of 50 participants after silicone removal was good in eyes that often had only light perception before the first procedure. The frequent cause of vision deterioration was cataract, improved with cataract extraction and $\mathrm{SO}$ removal.

\begin{tabular}{|l|l|l|}
\hline & $\begin{array}{l}\text { GroupA } \\
(\mathrm{n}=20)\end{array}$ & $\begin{array}{l}\text { Group B } \\
(\mathrm{n} 30)\end{array}$ \\
\hline $\begin{array}{l}\text { Changes in mean } \\
\text { VA } \\
\text { postoperative }\end{array}$ & $\begin{array}{l}0.1-0.2 \\
(.12)(\mathrm{P}<.000)\end{array}$ & $\begin{array}{l}0.1-0.12 \\
(\mathrm{P}<.000)\end{array}$ \\
\hline $\begin{array}{l}\text { Improvement in } \\
\text { PVR }\end{array}$ & $\begin{array}{l}\text { NO } \\
\text { Improvement } \\
(\mathrm{P}=.155)\end{array}$ & $\begin{array}{l}\text { Improved } \\
(\mathrm{P}<.000)\end{array}$ \\
\hline
\end{tabular}

Table-2 Data show visual and PVR Recovery of eyes in both treatment groups.

Survival analysis revealed that, the time onset of postoperative RD in the first 3-6 months after SO removal has no statistical difference between both groups $\mathrm{A}$ and $\mathrm{B}$ $(\mathrm{P}=.404)$ Fig-1

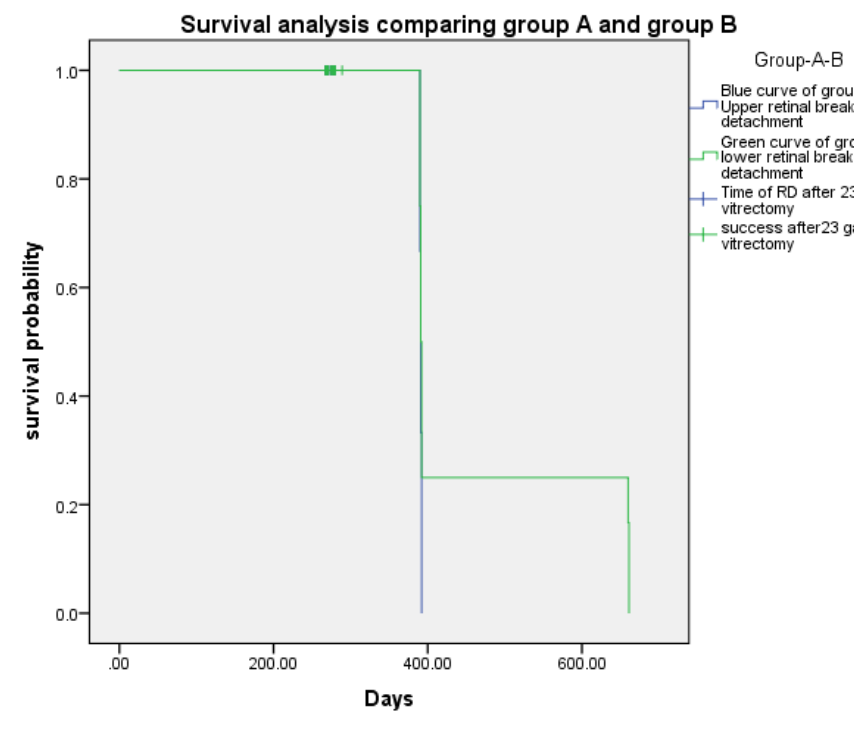

Fig-1. Kaplan-Meier survival analysis comparing group A (upper retinal break detachment) and group B (lower retinal break detachment) with respect to time of onset of RD after 23 gauge vitrectomy. No significant differences were observed $(\mathrm{P}=.404)$ between two treatment groups $(\mathrm{A}-\mathrm{B})$.

\section{DISCUSSION}

In this study we have 0.3 failure rate in all participants after the first 23gauge vitrectomy and SO removal. The failure rate was reduced to 0.2 after the second 23 gauge vitrectomy and
SO removal. Failure rate was ended after repeated vitrectomies and SO removal in the last three cases.

Multivariate analysis confirmed that there was statistical difference $(\mathrm{P}=.047)$ in the development of postoperative retinal detachment between the two groups after the first 23 gauge vitrectomy. The incidence of recurrent $\mathrm{RD}$ followed $\mathrm{SO}$ removal is variable: most studies have reported an incidence of $20-25 \%,{ }^{8}-12$ some $15-20 \%,{ }^{13,14}$ and a few below $10 \%{ }^{15,16}$. Identification and closure of all retinal breaks is the key for successful $\mathrm{PPV}^{17}$. Several mechanisms can explain the redetachment process, reopening of pre-existing breaks, or new retinal break formation, and residual vitreoretinal traction at the vitreous base ${ }^{18}$. In PPV, there is search for breaks in detached retina facilitated by wide-angle viewing systems, internal illumination and indentation. Most of these breaks are leading to redetachment that occurred after the initial operation. We have evidence that induction of PVD in macular hole surgery creates new retinal breaks and RD in 3 to $11 \%$ of patients ${ }^{19}$.

In this study PVR is the significant risk factor for recurrent $\mathrm{RD}$ while preoperative breaks and iatrogenic breaks were not risk factors. Despite that, these postoperative new breaks in recurrent $\mathrm{RD}$ seem to occur mostly in previously normallooking retina without apparent signs of retinal degeneration. The progression of PVD into normal areas with strong vitreoretinal adhesions share in inducing postoperative breaks ${ }^{20}$. These breaks are not missed breaks in previously attached retina ${ }^{21}$ or overlooked breaks ${ }^{22}$.Vitreous base shaving should be complete especially around the breaks and areas of peripheral retinal degeneration to reduce the recurrence in RD surgery ${ }^{23}$.

In both groups, the statistical difference in failure rate after the second 23- gauge vitrectomy is absent $(\mathrm{P}=.083)$. The new technology can help the different pathology in RD cases and improve the results. The using of a high-speed cutter can remove meticulously the PVD and the peripheral vitreous. Endolaser can give treatment of different extent (ranging from the equator to the ora serrata in all quadrants, to laser in three or four rows around the breaks) ${ }^{11}$. We have small series, and retrospective studies supporting 360 laser retinopexy ${ }^{24-26}$. In pseudophakic RD, 23- gauge vitrectomy can remove all vitreous traction on retinal tears and improved peripheral retina visualization $^{1}$

In addition, inferior detachments on average tend to be of longer duration and display a higher rate of preoperative intravitreal fibrocellular proliferations compared with detachments of the upper quadrants ${ }^{27}$. To improve the success rates of vitectomy in patients with breaks including the inferior quadrants, several suggestions have been published, including support of these breaks with an additional encircling band ${ }^{28}$, long-acting tamponades, e.g. C3F8, C2F6, silicone or heavy silicon $^{29-31}$. We believe that, the laser given for inferior break should be wide, extended from equator to the ora, if we have multiple inferior breaks the laser shots must be continuous around all breaks, broad more to nasal and temporal sides and if there is evidence of reproliferations like subretinal bands, the laser can be extended 360 degrees. Laser in lower retinal breaks should be satisfied, complete and broad. 
The preoperative visual acuity, preoperative ocular hypotony and the duration of macular detachment were the three best predictors of a good postoperative visual acuity. All participants have good visual acuity at 6 months after SO removal compared with the preoperative visual acuity. These results are comparable to most previous studies ${ }^{32-37}$.

Survival analysis in this study revealed that the follow up time in upper retinal break detachment was shorter compared with lower retinal break detachment. This is in agreement with Sigler et al and Ambiya,etal ${ }^{38}$.

\section{STUDY LIMITATION}

Although we aimed to accomplish this complete randomized clinical study, inclusion into this study is subject to selection bias and requires minimum follow up time (390-660 days).

The number of participants is not large despite that, the study is a mirror of our results of 23-gauge vitrectomy for RD in clinical setting.

\section{CONCLUSION}

The first 23- Gauge vitrectomy has less failure rate in upper retinal break detachment compared with lower retinal break detachment. Proliferative vitreoretinopathy is the significant risk factor for recurrent RD. All participants have good visual acuity at 6 months after SO removal compared with the preoperative visual acuity.

Trial registration: The trial is registered at Research Ethical Committee, Ain Shams University FWA000017585 FMASU25/2017, Registered at the US National Institutes of Health (ClinicalTrials.gov- ID: NCT04280770) February 20, 2020-'Retrospectively registered'.

Funding: None

\section{ACKNOWLEDGMENT}

Special thanks for Prof, Osama Raslan for his support and the given training.

\section{REFERENCES}

[1] Campo RV, Sipperley JO, Sneed SR, et al.:S Pars plana vitrectomy without scleral buckle for pseudophakic retinal detachments. Ophthalmology. 1999; 106:1811-1815.

[2] Martínez-Castillo, V, Boixadera, A, Verdugo, A, García-Arumí, J: Pars Plana Vitrectomy Alone for the Management of Inferior Breaks in Pseudophakic Retinal Detachment without

Facedown Position. Ophthalmology 2005;112:1222-1226

[3] Dell'Omo, R, Barca, F. Tan,S Bijl, HM, etal: Pars plana vitrectomy for the repair of primary, inferior rhegmatogenous retinal detachment associated to inferior breaks. A comparison of a 25-gauge versus a 20-gauge system. Graefes Arch Clin Exp Ophthalmol. 2013 Feb; 251(2): 485-490.

[4] Escoffery RF, Olk RJ, Grand MG, Boniuk I. Vitrectomy without scleral buckling for primary rhegmatogenous retinal detachment. Am J Ophthalmol 1985;99:275-81.

[5] Han, L, Cairns, JD, Campbell, WG, etal: Use of silicone oil in the treatment of complicated retinal detachment: Results from
1981 to 1994. Australian and New Zealand Journal of Ophthalmology (1998) 26, 299-304

[6] Krieglstein, GK, Robert N. Weinreb, RN, Stanislao Rizzo,S,etal: Vitreo-retinal Surgery progress III Ist ed 2009 Springer-Verlag Berlin Heidelberg, springer.com.

[7] Scholda,C, Egger, S Lakits,A etal: Retinal detachment after silicone oil removal Acta Ophthalmol. Scand. 2000: 78: 182186.

[8] Casswell AG, Gregor ZJ. Silicone oil removal. I. The effect on the complications of silicone oil. Br J Ophthalmol 1987; 71:893-7.

[9] Hutton WL, Azen SP, Blumenkranz MS, et al. The effects of silicone oil removal. Silicone study report 6 . Arch Ophthalmol 1994; 112:778-85.

[10] Scholda C, Egger S, Lakits A, et al. Retinal detachment after silicone oil removal.Acta Ophthalmol Scand 2000;78:182-6.

[11] Jonas JB, Knorr HL, Rank RM, Budde W M. Retinal redetachment after removal of intraocular silicone oil tamponade. Br J Ophthalmol 2001; 85:1203-7.

[12] Unlu“ N, Kocaog lan H, Acar MA, et al. Outcome of complex retinal detachment surgery after silicone oil removal. Int Ophthalmol 2004; 25:33-6.

[13] Franks WA, Leaver PK. Removal of silicone oil-rewards and penalties. Eye 1991; 5:333-7.

[14] Falkner CI, Binder S, Kruger A. Outcome after silicone oil removal. Br J Ophthalmol 2001; 85:1324-7.

[15] Zilis J, McCuen BW 2nd, de Juan ED Jr, et al. Results of silicone oil removal in advanced proliferative vitreoretinopathy. Am J Ophthalmol 1989; 108:15-21.

[16] Unlu“ N, Kocaog lan H, Acar MA, et al. Outcome of complex retinal detachment surgery after silicone oil removal. Int Ophthalmol 2004; 25:33-6.

[17] Fawcett IM, Williams RL, Wong D. Contact angles of substances used for internal tamponade in retinal detachment surgery. Graefes Arch Clin Exp Ophthalmol 1994;232:438-44.

[18] Hutton WL, Azen SP, Blumenkranz MS, et al. The effects of silicone oil removal. Silicone study report 6 . Arch Ophthalmol 1994; 112:778-85.

[19] Benson WE, Cruickshanks KC, Fong DS, etal: Surgical management of macular holes: a report by the American Academy of Ophthalmology. Ophthalmology. 2001 Jul;108(7):1328-35.

[20] Miki D, Hida T, Hotta K,etal: Comparison of scleral buckling and vitrectomy for retinal detachment resulting from flap tears in superior quadrants. Jpn J Ophthalmol 2001 45:187-191. DOI: 10.1016/s0021-5155(00)00377-4 PMID: 11313053.

[21] Richardson EC, Verma S, Green WT, etal: Primary vitrectomy for rhegmatogenous retinal detachment: an analysis of failure. Eur J Ophthalmol 2000 10:160-166.

[22] Lewis H, Aaberg TM Abrams G W: Causes of failure after repeat vitreoretinal surgery for severe proliferative vitreoretinopathy. Am J Ophthalmol 1991 111:15-19

[23] Teke MY, Balikoglu-Yilmaz M, Yuksekkaya P, etal.: Surgical outcomes and incidence of retinal redetachment in cases with complicated retinal detachment after silicone oil removal:Univariate and Multiple Risk Factors Analysis. RETINA 34:1926-1938, 2014

[24] Abu El-Asrar AM, Al-Bishi SM, Kangave D. Outcome of temporary silicone oil tamponade in complex rhegmatogenous retinal detachment. Eur J Ophthalmol 2003; 13:474-81.

[25] Nagpal MP, Videkar RP, Nagpal KM: Factors having implications on re-retinal detachments after silicone oil removal. Indian J Ophthalmol. 2012;60(6):517-520. 
[26] Ambresin A, Wolfensberger TJ, Bovey EH. Management of giant retinal tears with vitrectomy, internal tamponade and peripherial 360u retinal photocoagulation. Retina 2003; 23:6228.

[27] Brazitikos PD, Androudi S, Christen WG, Stangos NT. Primary pars plana vitrectomy versus scleral buckle surgery for the treatment of pseudophakic retinal detachment: a randomized clinical trial. Retina 2005;25(8):957-964.

[28] Tanner V, Minihan M, Williamson TH: Management of inferior retinal breaks during pars plana vitrectomy for retinal detachment. Br J Ophthalmol 2001 85:480-482.

[29] Gartry DS, Chignell AH, Franks WA, Wong D. Pars plana vitrectomy for the treatment of rhegmatogenous retinal detachment uncomplicated by advanced proliferative vitreoretinopathy. Br J Ophthalmol 1993 77:199-203.

[30] Schmidt JC, Rodrigues EB, Hoerle S, etal: Primary vitrectomy in complicated rhegmatogenous retinal detachment-a survey of 205 eyes. Ophthalmologica 2003 217:387-392.

[31] Wolf S, Schon V, Meier P, Wiedemann, P: Silicone oil-RMN3 mixture ("heavy silicone oil") as internal tamponade for complicated retinal detachment. Retina 2003 23:335-342.

[32] -Uemura A, Nakao K. A :comparison between scleral buckling procedure and vitrectomy for the management of uncomplicated retinal detachment caused by posterior retinal break. Nippon Ganka Gakkai Zasshi (J Jpn Ophthalmol Soc]1995;99:1170-4.
[33] Heimann H, Bornfeld N, Friedrichs W, et al. Primary vitrectomy without scleral buckling for rhegmatogenous retinal detachment. Graefes Arch Clin Exp Ophthalmol 1996;234:561-8.

[34] Tani P, Robertson DM, Langworthy A. Prognosis for central vision and anatomic reattachment in rhegmatogenous retinal detachment with macula detached. Am J Ophthalmol

1981;92:611-20.

[35] Brenton RS, Blodi CF. Prognosis of foveal splitting rhegmatogenous retinal detachments. Ophthalmic Surg 1989;20:112-4.

[36] Tornambe PE, Hilton GF, Brinton DA, et al. Pneumatic retinopexy: a two-year follow-up study of the multicenter clinical trial comparing pneumatic retinopexy with scleral buckling.Ophthalmology 1991;98:1115-23.

[37] Han DP, Mohsin NC, Guse CE, Hartz A, Tarkanian CN, The Southeastern Wisconsin Pneumatic Retinopexy Study Group. Comparison of pneumatic retinopexy and scleral buckling in the management of primary rhegmatogenous retinal detachment. Am J Ophthalmol 1998;126:658-68.

[38] Ambiya,V, Rani,PK, Narayanan,R,etal.:Outcomes of Recurrent Retinal Detachment Surgery following Pars Plana Vitrectomy for Rhegmatogenous Retinal Detachment (University of Florida)at11:0911November2017. DOI:10.1080/08820538.2017.1395893Science, 1989 